\title{
Telomerase regulation and the intimate relationship with aging
}

\author{
This article was published in the following Dove Press journal: \\ Research and Reports in Biochemistry \\ II June 2013 \\ Number of times this article has been viewed
}

\section{Garrett Morgan ${ }^{1-3}$ \\ 'Department of Physiology, University of Utah School of Medicine, University of Utah, ${ }^{2}$ George E. Wahlen Department of Veterans Affairs Medical Center, ${ }^{3}$ Geriatric Research, Education and Clinical Center, VA Salt Lake City Health Care System, Salt Lake City, UT, USA}

\begin{abstract}
Advancing age in humans is associated with a decline in function of physiological systems, as well as the onset and progression of many chronic diseases. An ongoing focus of basic aging research is to identify biomarkers that could be used to assess the severity of age-related diseases or that could also be modulated to treat them. Telomerase is an enzyme with mechanistic links to telomere length homeostasis and cell viability. Human telomerase is a ribonucleoprotein complex that consists of its catalytic subunit (hTERT) and ribonucleic acid template (hTERC). Telomerase adds de novo TTAGGG repeats to the ends of telomeres, which may prevent telomere shortening and subsequent dysfunction in certain cell compartments. Telomerase function within the cell represents a growing area of interest among biologists who study human aging, due to its potential use as a biomarker and therapeutic target for chronic disease. Here I review the basic biology of telomerase and the consequences of telomerase overexpression and deficiency in human cells and animal models. I discuss the putative role of telomerase in telomere-length homeostasis with advancing age in humans. Finally, I describe novel nontelomeric activities of telomerase related to cell viability and mitochondrial function.
\end{abstract}

Keywords: chronic disease, inflammation, oxidative stress, hTERT, hTERC, mitochondria

\section{Aging and chronic disease}

The US population is aging, and the number of older adults is expected to increase in the coming decades. ${ }^{1,2}$ Between 1980 and 2008, the population of adults in the US over the age of 65 increased from 25.6 to 38.9 million, while life expectancy after the age of 65 increased from 16.4 to 18.6 years. ${ }^{2}$ Importantly, the prevalence of chronic diseases like Alzheimer's disease, heart disease, stroke, and hypertension is reproducibly higher in older adults compared with younger adults. ${ }^{1-4}$ Thus, the anticipated increase in chronic-disease patients due to our aging population represents a major concern for the US healthcare system in the 21 st century. Many chronic diseases share some common pathological phenotypes, such as chronic inflammation and oxidative stress, as well as atrophy of the affected tissues. ${ }^{5-8}$ However, the molecular mechanisms that underlie these dysfunctional phenotypes are not completely understood. A better understanding of these mechanisms will lead to the identification of novel biomarkers that are predictive of chronic disease as well as lifestyle and pharmacological interventions to treat or even reverse age-related diseases in humans.

\section{Telomeres and telomerase}

Telomeres are TTAGGG repeats that make up the natural ends of chromosomes., ${ }^{9,10}$ Telomeres and telomere-binding proteins form specialized structures that protect 
chromosome ends from resembling double-stranded deoxyribonucleic acid (DNA) breaks and initiating the DNA break response. ${ }^{11-14}$ The DNA break response can induce apoptosis or cellular senescence through tumor suppressor protein 53 (P53)-mediated expression of cyclin-dependent kinase inhibitor 1A (P21). ${ }^{13,14}$ In vitro studies of human cells have clearly shown that disrupting telomere-binding proteins leads to telomere deprotection, P53 activation, and P53/P21-induced senescence. ${ }^{13,14}$ Several other studies have described a P53-mediated senescence-associated phenotype, characterized by increased production of pro-inflammatory mediators, such as tumor necrosis factor-alpha, interleukin 6, interleukin 8 , and monocyte chemotactic protein $1 .{ }^{15-19}$ Thus, telomere dysfunction could contribute to biological aging and chronic disease by inducing senescence ${ }^{13,14,20}$ and subsequent inflammatory phenotype in somatic tissues. ${ }^{15-19}$

Telomere shortening represents a potential mechanism by which telomere dysfunction could occur with advancing age. Due to the inability of the DNA replication machinery to copy the very distal ends of chromosomes, telomeres shorten with each cell cycle in most human tissues., ${ }^{90-24}$ Numerous in vitro studies have linked telomere shortening to senescence in human cells. ${ }^{9,20,25}$ Telomere shortening can also result from exposure to genotoxic stressors like reactive oxygen species (ROS), ${ }^{26}$ ultraviolet radiation, ${ }^{26}$ and nucleasedependent degradation. ${ }^{25,27,28}$ In human aging, oxidative stress occurs in many tissues from the accumulation of ROS, such as superoxide. ${ }^{5,8,29}$ Thus, chronic oxidative stress may be a particularly important mechanism underlying age-related telomere shortening in humans. ${ }^{26}$ In vivo, telomere shortening with advancing age that exceeds some critical telomere length might result in telomere dysfunction, which could lead to P53/P21-induced senescence, inflammation, and subsequent tissue dysfunction.

However, in certain tissues, telomere-length homeostasis is maintained over time by the enzyme telomerase..$^{30}$ First discovered by Elizabeth Blackburn in Tetrahymena, telomerase is a reverse transcriptase that adds de novo TTAGGG repeats to chromosome ends. ${ }^{31}$ Human telomerase is a ribonucleoprotein complex that consists of multiple components, including the catalytic subunit (hTERT), a ribonucleic acid (RNA) template component (hTERC), and various binding partners, such as dyskerin (DKC), telomerase cajal body protein 1 (TCAB1) and ribonucleoproteins NOP10, NHP2, and GAR1 (Figure 1). ${ }^{30,32}$ During the process of telomere elongation, hTERT uses hTERC as a template from which to extend telomeric repeats. The various binding partners perform functions related to the localization of telomerase to telomeres and stability of the

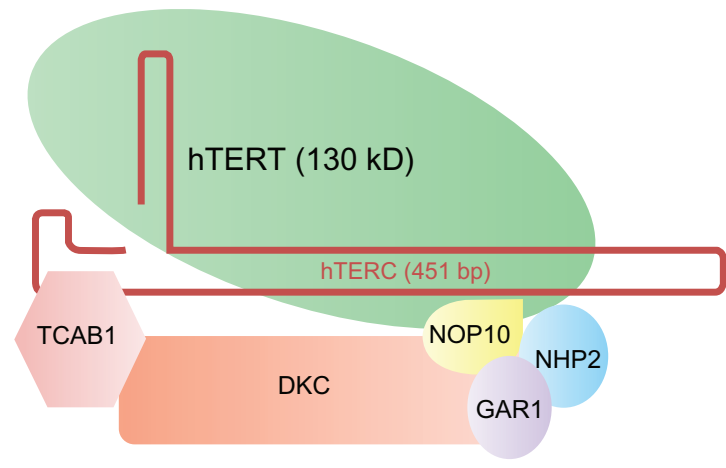

Figure I Human telomerase ribonucleoprotein complex.

Note: Human telomerase ribonucleoprotein complex with catalytic subunit (hTERT); RNA template (hTERC); binding partners dyskerin (DKC), NOPI0, NHP2, telomerase cajal body protein I (TCABI); and GARI.

Abbreviations: hTERT, human telomerase reverse transcriptase; hTERC, human telomerase RNA gene; bp, base pair; DKC, dyskerin; TCABI, telomerase cajal body protein I; RNA, ribonucleic acid.

telomerase complex during the telomere elongation process. TCAB1 helps recruit and stabilize hTERT to telomeres, ${ }^{33}$ while DKC, NHP2, GAR1, and NOP10 all appear to stabilize hTERC. ${ }^{34-37}$ Together, hTERT and these associated factors can efficiently add telomeric repeats to chromosome ends to compensate for telomere attrition.

While telomerase is constitutively active in germ cells, stem cells, and some somatic cells like white blood cells (WBCs), ${ }^{38-44}$ its expression and activity is negligible in most somatic tissues. ${ }^{45,46}$ High levels of telomerase expression and activity in somatic cells have been linked to neoplastic cell transformation in humans. ${ }^{47-53}$ Thus, the role of telomerase in normal aging and chronic disease is unclear and represents a growing area of research.

\section{In vitro telomerase activity in human cells}

Concomitant with cell cycle dependent telomere shortening, telomerase activity has been shown to decline as human cells become senescent in culture. ${ }^{54,55}$ This has led investigators to speculate that declines in telomerase activity may be a mechanism behind age-related telomere shortening, and maintenance of telomerase activity may extend the proliferative potential of cells. ${ }^{55}$ Indeed, telomerase overexpression results in immortalization of human fibroblasts in vitro. ${ }^{56,57}$ While the possibilities of extending tissue survival in vivo by overexpressing telomerase are intriguing, there is inherent risk in allowing cells to escape senescence, as this could lead to tumorigenesis. Elevated telomerase activity has been found in the early stages of lung, colon, prostate, and breast cancers. ${ }^{47,48,53}$ Additionally, mutations in telomerase-related genes and dysregulation of telomerase activity are suspected to 
play a role in the tumorigenesis of several common cancers. ${ }^{58-60}$ Thus, translating in vitro telomerase overexpression-dependent improvements in cell survival to increased tissue survival and lifespan in vivo in humans may be limited in its practicality.

\section{In vivo telomerase activity in mice Mouse models of telomerase overexpression}

Mouse models of telomerase overexpression have been generated and used to assess the effects of increased telomerase expression/activity on tissue survival and lifespan in mammals. One such model, recently reviewed by Geserick and Blasco, ${ }^{61}$ overexpresses mouse $(m)$ Tert under the control of the bovine keratin 5 (K5) gene promoter. ${ }^{62}$ The K5 mice are viable, fertile, and exhibit enhanced wound repair compared with wild type (WT) animals. ${ }^{62} \mathrm{~K} 5$ mice also exhibit higher rates of cell proliferation in response to mitogenic signals than WT controls, which is likely linked to the increased hyperplasia and neoplasia observed in a variety of tissues in $\mathrm{K} 5$ mice, as compared with WT controls. ${ }^{61} \mathrm{~K} 5$ mice have lower survival rates than WT controls, possibly related to the higher rates of tumorigenesis. ${ }^{61}$ However, individuals that survive past 75 weeks appear to have lower mortality and morbidity than WT counterparts. ${ }^{63}$ Interestingly, there is no difference in telomere length between K5 mice and WT mice. ${ }^{62}$

Another model of telomerase overexpression was recently described by Bernardes de Jesus et al. ${ }^{64}$ The authors showed that mice treated with adeno-associated virus expressing $m$ Tert lived longer and exhibited improved function in a variety of physiological systems. ${ }^{64}$ The animals displayed improved fitness, insulin sensitivity, bone density, and neuromuscular coordination compared with the control animals, and showed no signs of increased tumorigenesis. ${ }^{64}$ This exciting study represents the most convincing evidence to date that gene therapy aimed at increasing telomerase expression or activity could be useful for blunting age-related tissue dysfunction without increasing cancer risk.

\section{Mouse models of telomerase deficiency}

While models of telomerase overexpression have shown that increasing telomerase activity in vivo could be used to extend healthy lifespan in mammals, mouse models of telomerase deficiency have helped clarify the roles that telomerase and telomere-length homeostasis may play in normal tissue development, tissue function, and disease. WT mice have relatively long telomeres, high telomerase activity, and limited age-related telomere shortening compared with humans. ${ }^{61,65}$ This diminishes the utility of aged WT mice as a model of telomere shortening and telomerase function in humans. However, researchers have developed several transgenic mouse models of telomerase deficiency to mimic telomere shortening with advancing age in humans as well as many diseases linked to telomere dysfunction. ${ }^{38,44,66-72}$

Various models of mice deficient for the mTerc gene have been created that lack the catalytic subunit of telomerase. ${ }^{66-68}$ Another common model of telomerase deficiency involves deletion of the mTerc gene, which removes the RNA template from the telomerase complex..$^{38,44,69-72}$ Both versions of telomerase deficient mice develop similar phenotypes, including shortened telomeres, diminished tissue renewal in bone marrow, germ cells, and intestines, as well as impaired wound repair. ${ }^{38,44,66-72}$ To erode sufficiently the large telomere length reserve of mice, these mouse models of telomerase deficiency require breeding animals for multiple generations to attain the aforementioned phenotypes. ${ }^{38,44,66-72}$ While functional telomerase may not be essential for embryonic development in these mice, these phenotypes do occur at earlier time points in later generations of animals due to the inheritance of progressively shorter telomeres..$^{38,44,68,70}$ Combined with observations that telomerase deficiency appears most detrimental to stem cell compartments, ${ }^{38,44,70}$ this suggests that normal telomerase function may be most relevant for telomerelength homeostasis during early growth and development in mammals. ${ }^{42,73}$ During the growth and development of adult somatic tissues, cells are in a highly proliferative state, and the relatively high levels of telomerase activity may help cells counteract cell cycle-dependent telomere shortening. ${ }^{73}$ Although these studies do suggest that stem cell-mediated repair of adult somatic tissues may be an important physiology process negatively affected by reduced telomerase activity, a clear role for localized telomerase dysregulation in reduced tissue survival with advancing age or chronic disease remains elusive.

Interestingly, the general phenotypes of mTert and mTerc knockout mice resemble the etiology of a collection of blood disorders in humans, known as bone marrow failure syndrome (BMFS). BMFS includes, among other disorders, dyskeratosis congenita (DC), aplastic anemia (AA), myelodyplastic syndrome (MDS), ${ }^{74-76}$ and genetic screens have revealed that mutations in the human (h)TERT, hTERC, and DKC genes are linked to inherited forms of these disorders. ${ }^{77-80}$ These mutations are thought to lead to telomerase dysregulation and subsequent telomere dysfunction, which - in turn leads to depletion of stem cells and diminishes the repair and renewal capacity of somatic tissues. ${ }^{81}$ These effects are most pronounced in highly proliferative somatic tissues 
like hematopoietic stem cells in the bone marrow and result in a wide range of phenotypes including, but not limited to, mucosal leukoplakia, nail dystrophy, abnormal skin pigmentation, gastrointestinal atrophy, and tumors, as well as hematopoietic malignancies. ${ }^{74-76,81}$ Both mTERT and mTERC knockout mice develop their aforementioned phenotypes in a manner that is largely dependent on hematopoietic stem cell depletion in the bone marrow. ${ }^{38,44,70}$ Indeed, these mice may not be true models of normal human aging, but they have proved to be valuable tools for researchers interested in understanding the central role of telomerase in BMFS.

\section{Telomerase activity and human aging \\ Telomerase activity and telomere-length homeostasis in human aging}

As alluded to above, defining a role for telomerase in human aging has been difficult for researchers who study aging processes. An obvious issue with the hypothesis that telomerase preserves telomere-length homeostasis in adults is that telomere shortening occurs over time in most human somatic tissues. ${ }^{9,21,25}$ Another piece of evidence that is difficult to reconcile is the observation that telomerase expression levels are virtually undetectable in most fully differentiated human cells. ${ }^{46}$ Furthermore, animal and human studies have suggested that telomerase activity in adult mammals is only high enough to maintain telomere length homeostasis in germ and adult stem cell populations..$^{38,42,44,70,73}$ Within these cell compartments, telomerase may be important for preventing senescence by maintaining telomere-length integrity in highly proliferative cells, like spermatocytes or hematopoietic stem cells. ${ }^{42,44,70,73}$ Some studies have detected telomerase activity, as well as shown age-related declines, in WBCs from humans. ${ }^{41,43}$ As is the case with germ or stem cells, activated WBCs are highly proliferative compared with other somatic cells. ${ }^{39}$ This may explain the need for relatively high telomerase activity to maintain telomere length homeostasis in this cell compartment during an immune response. ${ }^{39,41}$ Thus, age-related declines in telomerase activity may compromise stem cell-mediated tissue repair, germ cell viability, and immune cell function in humans.

Another possibility is that telomerase activity in humans is most important for telomere-length homeostasis during early growth and development of somatic tissues, but it has limited relevance for tissue function and survival in adulthood. ${ }^{42,73}$ This prospect is strongly suggested by the animal studies described above and by Iwama et al, who showed, concomitant with progressive age-related telomere shortening, sharp age-related declines in telomerase activity in human WBCs up to the second decade of life. ${ }^{41}$ After around 20 years of age, WBC telomerase activity appears to level off and remains low or barely detectable through the ninth decade of life. ${ }^{41}$ While telomerase may not play a major role in telomere-length homeostasis with advancing age, a growing body of work suggests that telomerase may have important nontelomeric activities related to apoptosis resistance, cell proliferation control, and mitochondrial function in human cells. ${ }^{82}$

\section{Telomere-independent roles for telomerase activity in human aging Telomerase activity and cell proliferation/ apoptosis control in humans}

Several studies have suggested that telomerase can support cell proliferation in a variety of human cell types by regulating expression of mitogenic genes. ${ }^{83-85}$ Induced expression of telomerase has been shown to increase cell proliferation rates $^{85}$ and lead to increased expression of fibroblast growth factor (FGF) ${ }^{83}$ Furthermore, telomerase overexpression can maintain expression of keratinocyte growth factor and insulin-like growth factor in senescent human fibroblasts. ${ }^{84}$ Concomitant with increased FGF increases, Jin et al showed that fetal human fibroblasts had an increased tendency toward transformation, suggesting an increased risk of tumorigenesis following ectopic telomerase expression. ${ }^{83}$

Likewise, there is substantial evidence that telomerase confers apoptosis resistance in many different cell types. For example, hTERT overexpression has been shown to reduce apoptotic susceptibility in cardiomyocytes. ${ }^{86}$ The hTERT induction also suppresses apoptosis in smooth muscle cells and endothelial cells, with no evidence of increased tumorigenesis. ${ }^{87,88}$ Mattson et al suggest that hTERT suppresses apoptosis at a critical mitochondria-dependent step in neuronal cells, ${ }^{89}$ while Xi et al showed that expression of the dominant negative form of telomerase results in enhanced apoptosis in HeLa cells. ${ }^{90}$ The latter effect was likely due to an increase in the release of cytochrome $\mathrm{C}$ from the mitochondria. ${ }^{90}$ Collectively, the effects of telomerase on cell proliferation and apoptosis suggest mechanisms by which dysregulation of telomerase could be linked to human aging. Reduced ability of tissues to repair damage with advancing age could lead to tissue dysfunction and, ultimately, chronic disease. A major consideration to this interpretation of telomerase's role in aging is the inherent cancer risk with any antiaging therapy aimed at reducing apoptosis and increasing cell proliferation rates by modulating telomerase expression or activity. 


\section{Telomerase activity and mitochondrial function in humans}

Another telomere-independent function of telomerase that may have aging implications is the protection of mitochondria and mitochondrial DNA (mtDNA) from oxidative damage. ${ }^{91}$ The mitochondrial theory of aging maintains that, over time, oxidative damage to mitochondria and mtDNA leads to increased ROS inside cells, which, in turn, leads to age-related cell and tissue dysfunction. ${ }^{92-94}$ A vicious cycle is thought to occur whereby oxidatively damaged mitochondria generate and release more ROS, which further damages cell components, including the mitochondria, leading to even more ROS production. ${ }^{92,94}$ Thus, identifying endogenous mechanisms that protect cells and mitochondria from oxidative damage represents an ongoing goal of basic aging research, due to their inherent therapeutic potential.

A growing body of evidence supports a role for telomerase in mitochondrial homeostasis. Indeed, telomerase may perform crucial regulatory functions within mitochondria in human cells, as mitochondrial translocation of telomerase leads to improved mitochondrial function..$^{82,91,95-97}$ The improvement in function is likely mediated through mechanisms like reduced mitochondria-derived ROS, improved respiratory chain function, and increased mitochondrial membrane potential. ${ }^{91}$ The specific mechanisms by which telomerase improves mitochondrial function are unclear, but it has been shown to physically interact with and protect mtDNA from ROS in several different cell types. ${ }^{82,91,95}$ Telomerase has even been shown to facilitate mitochondrial transfer RNA processing. ${ }^{96}$ The beneficial effects of telomerase on mitochondrial function are putative mechanisms by which telomerase can protect cells from oxidative damage, as well as another plausible mechanism by which telomerase might confer apoptosis resistance by mitigating mitochondriadependent apoptosis. With respect to aging, modulation of telomerase interactions with mitochondria or telomerase expression with advancing age could lead to mitochondria dysfunction and increased oxidative stress in human cells and tissues.

\section{Telomerase activity and chronic disease}

While the role that telomerase plays in the normal aging process is currently unclear, telomerase dysregulation has been implicated in the etiology of some chronic diseases. Cardiovascular diseases (CVDs) are currently the most deadly diseases of aging in the US, and most deaths from CVDs are attributable to diseases of the arteries. ${ }^{4,98}$ An important study by Liu et al revealed elevated telomerase activity in atherosclerotic arteries compared with nonatherosclerotic controls. ${ }^{99}$ Likewise, Kroenke et al found that greater telomerase activity in WBCs was associated with greater CVD risk. ${ }^{100}$ These results are interesting because, similar to observations made in studies of telomerase and cancer risk, they suggest a maladaptive influence of increased telomerase activity and expression in the context of aging. However, age-related reductions in telomere length and telomerase activity in microglial cells from humans and rats suggest that telomerase may even play a role in Alzheimer's and dementias. ${ }^{101}$ Taken together, these studies indicate that while telomerase may not be particularly relevant to the normal aging process, there are clear implications for telomerase dysregulation in the pathogenesis of chronic diseases. Importantly, it appears that elevated telomerase activity may be detrimental in the context of aging and age-related disease, despite the predicted benefits to telomere-length homeostasis.

\section{Techniques for assessing telomerase activity in aging research}

In a laboratory setting, telomerase can be measured by a variety of methodologies. For the purposes of quantifying telomerase activity and expression in the context of clinical research, the most common techniques used include the telomeric repeat amplification protocol (TRAP) assay, ${ }^{41}$ Western blotting or quantitative reverse transcription polymerase chain reaction (RT-PCR) for expression of telomerase and related proteins and messenger RNA, ${ }^{46,91,102}$ respectively. These methods are largely sufficient for assessing overall telomerase function within a tissue of interest. Another technique that has been utilized involves performing chromatin immunoprecipitation (ChIP) to measure relative amounts of telomerase bound to telomeres. ${ }^{103}$ This technique allows investigators to obtain a fairly accurate picture of the in vivo function of telomerase within a cell. Indeed, ChIPs may be more informative for telomerase function than the TRAP assay or simple measures of telomerase expression, as changes in the amount of telomerase bound to telomeres should reflect the overall regulation of telomerase in response to an experimental condition. ${ }^{103,104}$ The caveat with using ChIPs to measure telomerase dynamics in a clinical research setting, is that these assays are technically difficult, time consuming, and expensive. ${ }^{104}$ Thus, using cheaper and more straightforward techniques, such as RT-PCR, may be a better option for some investigators. ${ }^{46}$ 


\section{Conclusion}

Telomere dysfunction is a potentially important mechanism underlying the aging phenotype in humans. Maintaining telomere-length homeostasis throughout an individual's life may improve tissue survival, ameliorate some chronic diseases, and even extend healthy lifespan. Thus, the dynamics of telomerase and telomere-binding proteins with advancing age have generated substantial interest among biologists who study basic aging processes, as they represent putative intervention targets to prevent or to reverse telomere dysfunction. However, the role of telomerase in normal telomere-length homeostasis and telomere dysfunction in humans remains uncertain, and interventions aimed at modulating telomerase expression and activity may not yet be feasible, due to the inherent cancer risk. An emerging body of research supports the hypothesis that telomerase has several important telomere independent activities within human cells, such as cell proliferation control, apoptosis resistance, and mitochondrial function (Figure 2). These nontelomeric functions of telomerase might ultimately comprise the more important roles for telomerase in cell and tissue dysfunction with advancing age. Thus, therapeutic interventions targeting nontelomeric pathways involving telomerase could be the safest way to manipulate telomerase activity to blunt or reverse age-related tissue dysfunction and chronic diseases in humans.

\section{Disclosure}

The author reports no conflicts of interest in this work.

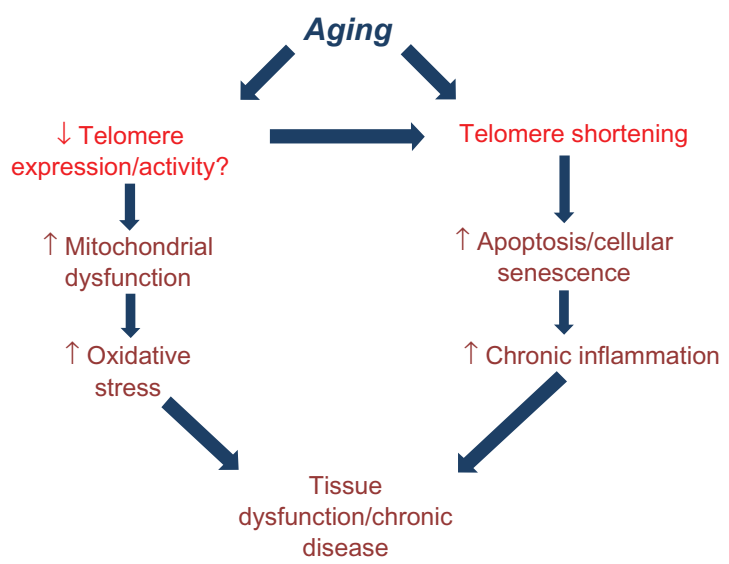

Figure 2 Telomere activity and human aging.

Notes: Conceptual diagram of telomerase's role in human aging and chronic disease. Dysregulation of telomerase activity or expression with advancing age could lead to telomere shortening, which in turn could cause senescence and apoptosis-mediated inflammation in certain cell compartments. Independent of its role in telomere shortening, age-related telomerase dysregulation could lead to mitochondrial dysfunction and increased oxidative stress. These effects could ultimately lead to tissue dysfunction and chronic disease with advancing age.

\section{References}

1. Vijg J, Campisi J. Puzzles, promises, and a cure for ageing. Nature. 2008;454(7208):1065-1071.

2. US Department of Health and Human Services. National Center for Health Statistics, With Special Feature on Death and Dying. Health. Hyattsville, MD. US Department of Health and Human Services; 2010. http://www.cdc.gov/nchs/data/hus/hus11.pdf. Accessed September 1, 2012.

3. Franklin SS, Gustin W IV, Wong ND, et al. Hemodynamic patterns of age-related changes in blood pressure. The Framingham Heart Study. Circulation. 1997;96(1):308-315.

4. Franklin SS, Larson MG, Khan SA, et al. Does the relation of blood pressure to coronary heart disease risk change with aging? The Framingham Heart Study. Circulation. 2001;103(9):1245-1249.

5. Campisi J, d'Adda di Fagagna F. Cellular senescence: when bad things happen to good cells. Nat Rev Mol Cell Biol. 2007;8(9):729-740.

6. Boekholdt SM, Peters RJ, Hack CE, et al. IL-8 plasma concentrations and the risk of future coronary artery disease in apparently healthy men and women: the EPIC-Norfolk prospective population study. Arterioscler Thromb Vasc Biol. 2004;24(8):1503-1508.

7. Donato AJ, Eskurza I, Silver AE, et al. Direct evidence of endothelial oxidative stress with aging in humans: relation to impaired endothelium-dependent dilation and upregulation of nuclear factorkappa B. Circ Res. 2007;100(11):1659-1666.

8. Fulle S, Protasi F, Di Tano G, et al. The contribution of reactive oxygen species to sarcopenia and muscle ageing. Exp Gerontol. 2004;39(1):17-24.

9. Harley $\mathrm{CB}$, Futcher AB, Greider CW. Telomeres shorten during ageing of human fibroblasts. Nature. 1990;345(6274):458-460.

10. de Lange T, Shiue L, Myers RM, et al. Structure and variability of human chromosome ends. Mol Cell Biol. 1990;10(2):518-527.

11. Stansel RM, de Lange T, Griffith JD. T-loop assembly in vitro involves binding of TRF2 near the 3' telomeric overhang. EMBO J. 2001;20(19):5532-5540.

12. Griffith JD, Comeau L, Rosenfield S, et al. Mammalian telomeres end in a large duplex loop. Cell. 1999;97(4):503-514.

13. d'Adda di Fagagna F, Reaper PM, Clay-Farrace L, et al. A DNA damage checkpoint response in telomere-initiated senescence. Nature. 2003;426(6963):194-198.

14. Takai H, Smogorzewska A, de Lange T. DNA damage foci at dysfunctional telomeres. Curr Biol. 2003;13(17):1549-1556.

15. Rodier F, Muñoz DP, Teachenor R, et al. DNA-SCARS: distinct nuclear structures that sustain damage-induced senescence growth arrest and inflammatory cytokine secretion. J Cell Sci. 2011;124(Pt 1):68-81.

16. Coppe JP, Patil CK, Rodier F, et al. Senescence-associated secretory phenotypes reveal cell-nonautonomous functions of oncogenic RAS and the p53 tumor suppressor. PLoS Biol. 2008;6(12):2853-2868.

17. Acosta JC, O'Loghlen A, Banito A, et al. Chemokine signaling via the CXCR2 receptor reinforces senescence. Cell. 2008;133(6): 1006-1018.

18. Liu D, Hornsby PJ. Senescent human fibroblasts increase the early growth of xenograft tumors via matrix metalloproteinase secretion. Cancer Res. 2007;67(7):3117-3126.

19. Noureddine H, Gary-Bobo G, Alifano M, et al. Pulmonary artery smooth muscle cell senescence is a pathogenic mechanism for pulmonary hypertension in chronic lung disease. Circ Res. 2011;109(5):543-553.

20. Baird DM, Rowson J, Wynford-Thomas D, Kipling D. Extensive allelic variation and ultrashort telomeres in senescent human cells. Nat Genet. 2003;33(2):203-207.

21. Chang E, Harley CB. Telomere length and replicative aging in human vascular tissues. Proc Natl Acad Sci U SA. 1995;92(24): 11190-11194.

22. Okuda K, Khan MY, Skurnick J, Kimura M, Aviv H, Aviv A. Telomere attrition of the human abdominal aorta: relationships with age and atherosclerosis. Atherosclerosis. 2000;152(2):391-398.

23. Ogami M, Ikura Y, Ohsawa M, et al. Telomere shortening in human coronary artery diseases. Arterioscler Thromb Vasc Biol. 2004;24(3): 546-550. 
24. Kimura M, Barbieri M, Gardner JP, et al. Leukocytes of exceptionally old persons display ultra-short telomeres. Am J Physiol Regul Integr Comp Physiol. 2007;293(6):R2210-R2217.

25. Sitte N, Saretzki G, von Zglinicki T. Accelerated telomere shortening in fibroblasts after extended periods of confluency. Free Radic Biol Med. 1998;24(6):885-893.

26. Oikawa S, Tada-Oikawa S, Kawanishi S. Site-specific DNA damage at the GGG sequence by UVA involves acceleration of telomere shortening. Biochemistry. 2001;40(15):4763-4768.

27. Hockemeyer D, Palm W, Wang RC, Couto SS, de Lange T. Engineered telomere degradation models dyskeratosis congenita. Genes Dev. 2008;22(13):1773-1785.

28. Wu L, Multani AS, He H, et al. Pot1 deficiency initiates DNA damage checkpoint activation and aberrant homologous recombination at telomeres. Cell. 2006;126(1):49-62.

29. Donato AJ, Black AD, Jablonski KL, Gano LB, Seals DR. Aging is associated with greater nuclear NF kappa B, reduced I kappa B alpha, and increased expression of proinflammatory cytokines in vascular endothelial cells of healthy humans. Aging Cell. 2008;7(6):805-812.

30. Nakamura TM, Morin GB, Chapman KB, et al. Telomerase catalytic subunit homologs from fission yeast and human. Science. 1997;277(5328):955-959.

31. Greider CW, Blackburn EH. Identification of a specific telomere terminal transferase activity in Tetrahymena extracts. Cell. 1985;43(2 Pt 1): 405-413.

32. Autexier C, Lue NF. The structure and function of telomerase reverse transcriptase. Annu Rev Biochem. 2006;75:493-517.

33. Stern JL, Zyner KG, Pickett HA, Cohen SB, Bryan TM. Telomerase recruitment requires both TCAB1 and Cajal bodies independently. Mol Cell Biol. 2012;32(13):2384-2395.

34. Walne AJ, Vulliamy T, Marrone A, et al. Genetic heterogeneity in autosomal recessive dyskeratosis congenita with one subtype due to mutations in the telomerase-associated protein NOP10. Hum Mol Genet 2007;16(13):1619-1629.

35. Machado-Pinilla R, Carrillo J, Manguan-Garcia C, et al. Defects in mTR stability and telomerase activity produced by the Dkc1 A353V mutation in dyskeratosis congenita are rescued by a peptide from the dyskerin TruB domain. Clin Transl Oncol. 2012;14(10):755-763.

36. Pogacic V, Dragon F, Filipowicz W. Human H/ACA small nucleolar RNPs and telomerase share evolutionarily conserved proteins NHP2 and NOP10. Mol Cell Biol. 2000;20(23):9028-9040.

37. Egan ED, Collins K. Specificity and stoichiometry of subunit interactions in the human telomerase holoenzyme assembled in vivo. Mol Cell Biol. 2010;30(11):2775-2786.

38. Hao LY, Armanios M, Strong MA, et al. Short telomeres, even in the presence of telomerase, limit tissue renewal capacity. Cell. 2005;123(6): 1121-1131.

39. Hiyama K, Hirai Y, Kyoizumi S, et al. Activation of telomerase in human lymphocytes and hematopoietic progenitor cells. J Immunol. 1995;155(8):3711-3715.

40. Ly H, Calado RT, Allard P, et al. Functional characterization of telomerase RNA variants found in patients with hematological disorders. Blood. 2005;105(6):2332-2339.

41. Iwama H, Ohyashiki K, Ohyashiki JH, et al. Telomeric length and telomerase activity vary with age in peripheral blood cells obtained from normal individuals. Hum Genet. 1998;102(4):397-402.

42. Liu L, Bailey SM, Okuka M, et al. Telomere lengthening early in development. Nat Cell Biol. 2007;9(12):1436-1441.

43. Ohyashiki K, Ohyashiki JH, Nishimaki J, et al. Cytological detection of telomerase activity using an in situ telomeric repeat amplification protocol assay. Cancer Res. 1997;57(11):2100-2103.

44. Lee HW, Blasco MA, Gottlieb GJ, Horner JW 2nd, Greider CW, DePinho RA. Essential role of mouse telomerase in highly proliferative organs. Nature. 1998;392(6676):569-574.

45. Ahmed A, Tollefsbol T. Telomeres and telomerase: basic science implications for aging. J Am Geriatr Soc. Aug 2001;49(8): 1105-1109.
46. Meyerson M, Counter CM, Eaton EN, et al. hEST2, the putative human telomerase catalytic subunit gene, is up-regulated in tumor cells and during immortalization. Cell. 1997;90(4):785-795.

47. Winnikow EP, Medeiros LR, Edelweiss MI, et al. Accuracy of telomerase in estimating breast cancer risk: a systematic review and meta-analysis. Breast. 2012;21(1):1-7.

48. Shay JW. Telomerase in human development and cancer. J Cell Physiol. 1997;173(2):266-270.

49. Jiang J, Wei LH, Li YL, et al. Detection of TERC amplification in cervical epithelial cells for the diagnosis of high-grade cervical lesions and invasive cancer: a multicenter study in China. J Mol Diagn. 2010;12(6):808-817.

50. Hiyama T, Yokozaki H, Kitadai Y, et al. In situ mRNA hybridization technique for analysis of human telomerase RNA in gastric precancerous and cancerous lesions. Jpn J Cancer Res. 1998;89(11):1187-1194.

51. Cogulu O, Kosova B, Karaca E, et al. Evaluation of telomerase mRNA (hTERT) in childhood acute leukemia. Leuk Lymphoma. 2004;45(12):2477-2480.

52. Miura N, Osaki Y, Nagashima M, et al. A novel biomarker TERTmRNA is applicable for early detection of hepatoma. BMC Gastroenterol. 2010;10:46.

53. Van den Berg RM, Brokx H, Vesin A, et al. Prognostic value of hTERT mRNA expression in surgical samples of lung cancer patients: the European Early Lung Cancer Project. Int J Oncol. 2010;37(2):455-461.

54. Holt SE, Wright WE, Shay JW. Regulation of telomerase activity in immortal cell lines. Mol Cell Biol. 1996;16(6):2932-2939.

55. Holt SE, Aisner DL, Shay JW, Wright WE. Lack of cell cycle regulation of telomerase activity in human cells. Proc Natl Acad Sci U S A. 1997;94(20):10687-10692.

56. Vaziri H, Benchimol S. Reconstitution of telomerase activity in normal human cells leads to elongation of telomeres and extended replicative life span. Curr Biol. 1998;8(5):279-282.

57. Bodnar AG, Ouellette M, Frolkis M, et al. Extension of life-span by introduction of telomerase into normal human cells. Science. 1998;279(5349):349-352.

58. Alter BP, Giri N, Savage SA, Rosenberg PS. Cancer in dyskeratosis congenita. Blood. 2009;113(26):6549-6557.

59. Zou P, Gu A, Ji G, Zhao L, Zhao P, Lu A. The TERT rs 2736100 polymorphism and cancer risk: a meta-analysis based on 25 case-control studies. BMC Cancer. 2012;12:7.

60. Mocellin S, Verdi D, Pooley KA, et al. Telomerase reverse transcriptase locus polymorphisms and cancer risk: a field synopsis and metaanalysis. J Natl Cancer Inst. 2012;104(11):840-854.

61. Geserick C, Blasco MA. Novel roles for telomerase in aging. Mech Ageing Dev. 2006;127(6):579-583.

62. González-Suárez E, Samper E, Ramirez A, et al. Increased epidermal tumors and increased skin wound healing in transgenic mice overexpressing the catalytic subunit of telomerase, mTERT, in basal keratinocytes. EMBO J. 2001;20(11):2619-2630.

63. González-Suárez E, Geserick C, Flores JM, Blasco MA. Antagonistic effects of telomerase on cancer and aging in K5-mTert transgenic mice. Oncogene. 2005;24(13):2256-2270.

64. Bernardes de Jesus B, Vera E, Schneeberger K, et al. Telomerase gene therapy in adult and old mice delays aging and increases longevity without increasing cancer. EMBO Mol Med. 2012;4(8):691-704.

65. Prowse KR, Greider CW. Developmental and tissue-specific regulation of mouse telomerase and telomere length. Proc Natl Acad Sci USA. 1995;92(11):4818-4822.

66. Liu Y, Snow BE, Hande MP, et al. The telomerase reverse transcriptase is limiting and necessary for telomerase function in vivo. Curr Biol. 2000;10(22):1459-1462.

67. Yuan X, Ishibashi S, Hatakeyama S, et al. Presence of telomeric G-strand tails in the telomerase catalytic subunit TERT knockout mice. Genes Cells. 1999;4(10):563-572.

68. Erdmann N, Liu Y, Harrington L. Distinct dosage requirements for the maintenance of long and short telomeres in mTert heterozygous mice. Proc Natl Acad Sci U S A. 2004;101(16):6080-6085. 
69. Blasco MA, Lee HW, Hande MP, et al. Telomere shortening and tumor formation by mouse cells lacking telomerase RNA. Cell. 1997;91(1):25-34.

70. Herrera E, Samper E, Martin-Caballero J, Flores JM, Lee HW, Blasco MA. Disease states associated with telomerase deficiency appear earlier in mice with short telomeres. EMBO J. 1999;18(11):2950-2960.

71. Niida H, Matsumoto T, Satoh H, et al. Severe growth defect in mouse cells lacking the telomerase RNA component. Nat Genet. 1998; 19(2):203-206.

72. Rudolph KL, Chang S, Lee HW, et al. Longevity, stress response, and cancer in aging telomerase-deficient mice. Cell. 1999;96(5):701-712.

73. Ulaner GA, Giudice LC. Developmental regulation of telomerase activity in human fetal tissues during gestation. Mol Hum Reprod. 1997;3(9):769-773.

74. Dokal I. Dyskeratosis congenita in all its forms. $\mathrm{Br} J$ Haematol. 2000;110(4):768-779.

75. Marrone A, Sokhal P, Walne A, et al. Functional characterization of novel telomerase RNA (TERC) mutations in patients with diverse clinical and pathological presentations. Haematologica. 2007;92(8):1013-1020.

76. Young NS. Acquired aplastic anemia. Ann Intern Med. 2002;136(7): 534-546.

77. Savage S, Stewart B, Weksler B, et al. Mutations in the reverse transcriptase component of telomerase (TERT) in patients with bone marrow failure. Blood Cells Mol Dis. 2006;37(2):134-136.

78. Knight SW, Vulliamy TJ, Morgan B, Devriendt K, Mason PJ, Dokal I. Identification of novel DKC1 mutations in patients with dyskeratosis congenita: implications for pathophysiology and diagnosis. Hum Genet. 2001;108(4):299-303.

79. Wilson DB, Ivanovich J, Whelan A, Goodfellow PJ, Bessler M. Human telomerase RNA mutations and bone marrow failure. Lancet. 2003;361(9373):1993-1994.

80. Yamaguchi H, Calado, RT, Ly H, et al. Mutations in TERT, the gene for telomerase reverse transcriptase, in aplastic anemia. New Engl J Med. 2005;352(14):1413-1424.

81. Carroll KA, Ly H. Telomere dysfunction in human diseases: the long and short of it! Int J Clin Exp Pathol. 2009;2(6):528-543.

82. Haendeler J, Dröse S, Büchner N, et al. Mitochondrial telomerase reverse transcriptase binds to and protects mitochondrial DNA and function from damage. Arterioscler Thromb Vasc Biol. 2009;29(6):929-935.

83. Jin X, Beck S, Sohn YW, et al. Human telomerase catalytic subunit (hTERT) suppresses p53-mediated anti-apoptotic response via induction of basic fibroblast growth factor. Exp Mol Med. 2010;42(8):574-582.

84. Kanzaki Y, Onoue F, Ishikawa F, Ide T. Telomerase rescues the expression levels of keratinocyte growth factor and insulin-like growth factor-II in senescent human fibroblasts. Exp Cell Res. 2002;279(2):321-329.

85. Xiang H, Wang J, Mao Y, Liu M, Reddy VN, Li DW. Human telomerase accelerates growth of lens epithelial cells through regulation of the genes mediating RB/E2F pathway. Oncogene. 2002;21(23):3784-3791.

86. Oh H, Taffet GE, Youker KA, et al. Telomerase reverse transcriptase promotes cardiac muscle cell proliferation, hypertrophy, and survival. Proc Natl Acad Sci US A. 2001;98(18):10308-10313.

87. Werner C, Gensch C, Pöss J, Haendeler J, Böhm M, Laufs U. Pioglitazone activates aortic telomerase and prevents stress-induced endothelial apoptosis. Atherosclerosis. 2011;216(1):23-34.
88. Wu X, Song B, Zhang J, et al. Human telomerase reverse transcriptase transfection reduces apoptosis in human penile smooth muscle cells and slows down cellular aging. J Sex Med. 2012;9(2):494-504.

89. Mattson MP, Fu W, Zhang P. Emerging roles for telomerase in regulating cell differentiation and survival: a neuroscientist's perspective. Mech Ageing Dev. 2001;122(7):659-671.

90. Xi L, Chen $\mathrm{G}$, Zhou J, et al. Inhibition of telomerase enhances apoptosis induced by sodium butyrate via mitochondrial pathway. Apoptosis. 2006;11(5):789-798.

91. Ahmed S, Passos JF, Birket MJ, et al. Telomerase does not counteract telomere shortening but protects mitochondrial function under oxidative stress. J Cell Sci. 2008;121(Pt 7):1046-1053.

92. Wei YH, Ma YS, Lee HC, Lee CF, Lu CY. Mitochondrial theory of aging matures - roles of mtDNA mutation and oxidative stress in human aging. Zhonghua Yi Xue Za Zhi (Taipei). 2001;64(5):259-270.

93. Jacobs HT. The mitochondrial theory of aging: dead or alive? Aging Cell. 2003;2(1):11-17.

94. Loeb LA, Wallace DC, Martin GM. The mitochondrial theory of aging and its relationship to reactive oxygen species damage and somatic mtDNA mutations. Proc Natl Acad Sci U S A. 2005;102(52):18769-18770.

95. Ling X, Wen L, Zhou Y. Role of mitochondrial translocation of telomerase in hepatocellular carcinoma cells with multidrug resistance. Int J Med Sci. 2012;9(7):545-554.

96. Sharma NK, Reyes A, Green P, et al. Human telomerase acts as a hTR-independent reverse transcriptase in mitochondria. Nucleic Acids Res. 2012;40(2):712-725.

97. Kovalenko OA, Caron MJ, Ulema P, et al. A mutant telomerase defective in nuclear-cytoplasmic shuttling fails to immortalize cells and is associated with mitochondrial dysfunction. Aging Cell. 2010;9(2):203-219.

98. Franklin SS, Lopez VA, Wong ND, et al. Single versus combined blood pressure components and risk for cardiovascular disease: the Framingham Heart Study. Circulation. 2009;119(2):243-250.

99. Liu SC, Wang SS, Wu MZ, et al. Activation of telomerase and expression of human telomerase reverse transcriptase in coronary atherosclerosis. Cardiovasc Pathol. 2005;14(5):232-240.

100. Kroenke $\mathrm{CH}$, Pletcher MJ, Lin J, et al. Telomerase, telomere length, and coronary artery calcium in black and white men in the CARDIA study. Atherosclerosis. 2012;220(2):506-512.

101. Flanary BE, Sammons NW, Nguyen C, Walker D, Streit WJ. Evidence that aging and amyloid promote microglial cell senescence. Rejuvenation Res. 2007;10(1):61-74.

102. Xiao Y, Gao J, Gao K, et al. [Establishment of a pulmonary metastasis model of melanoma with stably expressed hTERT/Luc.] Xi Bao Yu Fen Zi Mian Yi Xue Za Zhi. 2013;29(1):89-92. Chinese [with English abstract].

103. Hirai Y, Masutomi K, Ishikawa F. Kinetics of DNA replication and telomerase reaction at a single-seeded telomere in human cells. Genes Cells. 2012;17(3):186-204.

104. Dahl JA, Collas P. A rapid micro chromatin immunoprecipitation assay (microChIP). Nat Protoc. 2008;3(6):1032-1045.
Research and Reports in Biochemistry

\section{Publish your work in this journal}

Research and Reports in Biochemistry is an international, peer-reviewed, open access journal publishing original research, reports, reviews and commentaries on all areas of biochemistry. The manuscript management system is completely online and includes a very quick and fair
Dovepress

peer-review system. Visit http://www.dovepress.com/testimonials.php to read real quotes from published authors. 